\title{
Dexamethasone-induced apoptosis of freshly isolated human nasal epithelial cells concomitant with abrogation of IL-8 production*
}

\author{
S. Bobic ${ }^{1}$, C.M. van Drunen ${ }^{2}$, I. Callebaut ${ }^{1}$, V. Hox ${ }^{1}$, M. Jorissen ${ }^{3}$, W.J. Fokkens ${ }^{2}$, \\ P.W. Hellings ${ }^{1,3}$ \\ 1 Laboratory of Experimental Immunology, Catholic University Hospitals, Leuven, Belgium \\ 2 Department of Otorhinolaryngology, Academic Medical Center, Amsterdam, the Netherlands \\ 3 Department of Otorhinolaryngology, Head and Neck Surgery, Catholic University Hospitals, Leuven, Belgium
}

SUMMARY

\begin{abstract}
Background: Human nasal epithelial cells (hNECS) are the first line of immune defense and are able to produce mediators that recruit, activate and prolong survival of immune cells, among which IL-8 takes an important place. This study investigates the contribution of freshly isolated hNECs to IL-8 production in chronic rhinosinusitis with nasal polyps (CRSwithNP). Secondly, the effects of dexamethasone treatment on hNEC apoptosis and IL-8 production are investigated.
\end{abstract}

Methodology: hNECs were isolated from nasal polyps and healthy inferior turbinate of NP patients and from inferior turbinates of healthy donors by protease treatment and two negative selection procedures. $h N E C s$ were incubated with $I L-1 \beta$, TNF- $\alpha$ or dexamethasone. After $24 h$, $I L-8$ levels were determined in the supernatants by ELISA. Finally, hNECs were incubated with increasing doses of dexamethasone and apoptosis was studied.

Results: hNECs isolated from nasal turbinates of healthy and NP patients and polyp tissue from NP patients produced similar levels of IL-8. IL-1 $\beta$ induced higher levels of IL-8 production in all types of hNECs without differences between control and NP tissue. Dexamethasone induced apoptosis of hNECs concomitant with abrogation of IL-8 production by $h N E C$.

Conclusions: IL-8 production by human nasal epithelial cells does not differ between NP and healthy tissue under baseline nor stimulatory conditions. Dexamethasone induces apoptosis of hNECs and abrogates IL-8 production.

Key words: IL-8, human nasal epithelial cells (hNECs), chronic rhinosinusitis with nasal polyps (CRSwithNP) and dexamethasone

\section{INTRODUCTION}

Epithelial cells lining the nasal cavity have a pivotal role in detecting and responding to various environmental stimuli. Nasal epithelial cells are more than just a physical barrier. They exert their immunological function by producing various cytokines and growth factors that enable the recruitment and effector function of immune cells ${ }^{(1)}$. In addition, supernatants from cultured nasal or airway epithelial cells have been shown to prolong the survival of neutrophils ${ }^{(2)}$ and eosinophils ${ }^{(3)}$. Many authors have studied airway epithelial cell biology using either immortalized cell lines ${ }^{(1,4-6)}$ or freshly isolated nasal/airway epithelial cells. In most studies, primary epithelial cells obtained by positive selection are grown for 6-14 days in a medium rich in growth factors and mediators that stimulate growth of epithelial cells and apoptosis of other cell types ${ }^{(2,6-9)}$.
Although these techniques yield 99,5\% pure epithelial cell cultures, long term incubation might introduce immunological alterations in parallel with variations in phenotypical aspects of epithelial cells ${ }^{(10-12)}$. Here we build further on a recently reported novel technique of isolation and purification of primary nasal epithelial cells (hNECs) using two negative selections ${ }^{(13)}$. Epithelial cells were freshly isolated and incubated to study the contribution of human nasal epithelial cells (hNECs) to IL-8 production in chronic rhinosinusitis with nasal polyps (CRSwithNP).

IL-8 is one of the major cytokines secreted by epithelial cells upon stimulation. It is mainly produced upon stimulation of the toll-like receptors (TLRs) on the surface of the epithelial cells by an antigen ${ }^{(14)}$ or microbial products. Super-antigens Staphylococcus aureus enterotoxin A (SEA) and B (SEB) ${ }^{(15)}$ 
and pro-inflammatory cytokines such as IL- $1 \beta^{(5,16)}$, TNF- $\alpha{ }^{(8,16)}$ and IL-17 ${ }^{(17,18)}$ can induce or modulate IL- 8 production by human epithelial cells. Endothelin-1 ${ }^{(19)}$ and VIP ${ }^{(20)}$ were also shown to be potent inducers of IL-8 in human nasal epithelial cells. IL- 8 acts through the G protein-coupled serpentine receptors CXCR1 and CXCR2 and its primary function is the recruitment of neutrophils to the site of inflammation. It is also known as neutrophil-chemotactic factor or CXCL8 ${ }^{(21)}$.

CRSwithNP is characterised by a Th2 type inflammation associated with high levels of IL-8 and neutrophils in NP tissue ${ }^{(22)}$. It has been shown that IL-8 is up-regulated in CRS patients with NP being mainly produced by epithelial cells and eosinophils ${ }^{(23,24)}$. IL-8 is the major chemo-attractant factor for neutrophils, but the precise contribution of neutrophil influx in NP disease remains obscure. By releasing TGF- $\beta^{(25)}$ and matrix metalloproteinase $9^{(26)}$, neutrophils contribute to the reorganization of the extracellular matrix and the pathology of NP disease.

In this study, we aimed to investigate the effect of dexamethasone on nasal epithelial cell survival and IL-8 production. Dexamethasone represents a corticosteroid with broad antiinflammatory potential. The use of corticosteroids in the treatment of NP disease is wide-spread as it is the only currently available treatment option with proven efficacy in NP ${ }^{(27)}$. Dorscheid et al. described dexamethasone-induced apoptosis of airway epithelial cells, in both primary and immortalized cell lines ${ }^{(6)}$. In addition, it has been shown that dexamethasone reduces the levels of IL-8 in human airway epithelial cells by different mechanisms: up-regulating glucocorticoid-induced leucine zipper (GILZ) which inhibits the transcription of NF$\kappa \mathrm{B}^{(28)}$, by inhibiting the binding of NF- $\textrm{B}$ transcription factor to its responsive elements ${ }^{(29)}$ or by destabilizing the IL-8 mRNA transcript ${ }^{(30)}$. In addition, bacterial products such as LPS and peptidoglycans increase the activity NF- $\mathrm{B}$ in paranasal sinus epithelial cells which is suppressed by pre-incubation with dexamethasone ${ }^{(31)}$. However, there are reports of corticosteroid treatment inducing higher production of IL-8 in airway epithelial cells of asthmatic patients together with neutrophilic airway inflammation being associated with unresponsiveness to corticosteroid therapy ${ }^{(32)}$.

Table 1. Patients' characteristics.

\begin{tabular}{lcc}
\hline & $\begin{array}{c}\text { Control patients } \\
(\mathrm{n}=19)\end{array}$ & $\begin{array}{c}\text { NP patients } \\
(\mathrm{n}=12)\end{array}$ \\
\hline Females & $7 / 19(37 \%)$ & $6 / 12(50 \%)$ \\
Nasal corticosteroids & $7 / 19(37 \%)$ & $10 / 12(83 \%)$ \\
Atopy & $7 / 19(37 \%)$ & $6 / 12(50 \%)$ \\
Asthma & $1 / 19(5 \%)$ & $5 / 12(42 \%)$ \\
AIA & $0 / 19(0 \%)$ & $2 / 12(17 \%)$ \\
Current smokers & $4 / 19(21 \%)$ & $3 / 12(25 \%)$ \\
\hline
\end{tabular}

* Patients are characterized by the presence of atopy, asthma (or AIA aspirin-induced asthma syndrome), smoking habits and usage of nasal corticosteroids.

\section{METHODS}

\section{Patients' characteristics}

Nasal biopsies were taken from patients during surgery, after a written informed consent was obtained. A biopsy of the inferior turbinate and a piece of nasal polyp tissue were taken during surgery from CRS patients with nasal polyps (CRSwithNP, $\mathrm{n}=$ 12), while a biopsy of the inferior turbinate was obtained from healthy control patients $(n=19)$ without endoscopic evidence of CRSwithNP who underwent surgery for anatomical or aesthetical reasons. Patients' characteristics are listed in Table 1. The diagnosis of atopy was based on positive skin prick test results for a panel of 18 common inhalant allergens (HAL Allergy, Leiden, The Netherlands). The diagnosis of aspirinintolerance and asthma were history based. The study was approved by the ethical committee of the Catholic University Hospital Leuven.

\section{Isolation and stimulation of nasal epithelial cells (NECS)}

A highly purified epithelial cell population was obtained by the following procedure (Figure 1) as reported previously ${ }^{(13)}$. Tissue was washed in sterile saline and enzymatically digested in $0.1 \%$ pronase (Protease XIV, Sigma) solution in culture medium (Lonza BioWhittaker DMEM) supplemented with L-Glutamine, $100 \mathrm{U} / \mathrm{ml}$ penicillin, $100 \mu \mathrm{g} / \mathrm{ml}$ streptomycin, and $2 \%(\mathrm{v} / \mathrm{v})$ ultroser $\mathrm{G}$. After overnight incubation at $4^{\circ} \mathrm{C}$ with shaking, the protease reaction was stopped by the addition of FCS (1:10 (v/v)). Cells were washed in culture medium and pelleted by centrifugation for $5 \mathrm{~min}$ on $800 \mathrm{rpm}$. Washed cells were re-suspended in $10 \mathrm{ml}$ culture medium and incubated in a plastic culture flask for $1 \mathrm{~h}$ at $37^{\circ} \mathrm{C}$ in a cell incubator to remove the fibroblasts. The cell suspension was mixed with $2 \times 10^{7}$ prewashed CD45-magnetic beads (Dynabeads ${ }^{\circledR}$ CD45, Invitrogen) and epithelial cells were purified by the negative selection following the manufacturer's instructions (Figure 1). Cell purity was verified by cytospin preparations and was found to be $\geq 98 \%$. The final cell suspension was centrifuged and re-suspended in $1 \mathrm{ml}$ culture medium.

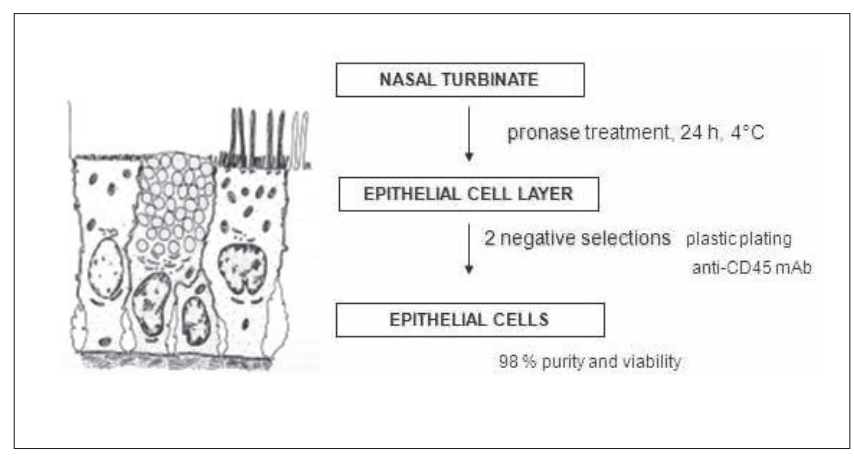

Figure 1. Purification procedure of human nasal epithelial cells (hNECs) 


\section{Epithelial stimulation procedure}

Purified human nasal epithelial cells (hNECs) were counted in the Bürker's chamber and different numbers of hNECs (1 $\mathrm{x}$ $10^{5}, 5 \times 10^{5}, 1 \times 10^{6}$ ) were incubated in $1 \mathrm{ml}$ culture medium with or without IL-1 $\beta(10 \mathrm{ng} / \mathrm{ml})$ and TNF- $\alpha(10 \mathrm{ng} / \mathrm{ml})$ for 24 $\mathrm{h}$ at $37^{\circ} \mathrm{C}$. Pilot studies involving different concentrations of IL- $1 \beta$ and TNF- $\alpha$ showed that $10 \mathrm{ng} / \mathrm{ml}$ was the optimal dose for stimulation of hNECs (data not shown). Additionally, three different concentrations of hNECs $\left(1 \times 10^{5}, 5 \times 10^{5}\right.$ and $1 \times 10^{6}$ cells $/ \mathrm{ml}$ ) were incubated with increasing doses of dexamethasone $(10,100,1000 \mu \mathrm{g} / \mathrm{ml})$ for $24 \mathrm{~h}$ at $37^{\circ} \mathrm{C}$.

\section{Evaluation of IL-8 production}

After $24 \mathrm{~h}$ incubation of hNECs in different conditions with/without pro-inflammatory cytokines or dexamethasone, supernatants were harvested and stored at $-20^{\circ} \mathrm{C}$ until subsequent analysis. IL-8 was measured in the supernatants of hNECs by sandwich ELISA (capture antibody G265-5 (554716), biotinylated detection antibody G265-8 (554718), rhIL-8 as standard (554609), BD Pharmingen ${ }^{\text {TM }}$, BD Bioscience).

\section{Apoptosis assay}

In a separate series of experiments, $1 \times 10^{5}$ cells $/ \mathrm{ml}$ of freshly isolated hNECs from inferior turbinate of four healthy donors were incubated with increasing doses of dexamethasone (10, $100,1000 \mu \mathrm{g} / \mathrm{ml}$ ) or medium for $6 \mathrm{~h}$ or $24 \mathrm{~h}$ on $37^{\circ} \mathrm{C}$. Cells were subsequently washed and the number of viable cells was determined by trypan-blue staining after $24 \mathrm{~h}$. To estimate the degree of apoptosis, cells were stained with annexin V-FITC and propidium-iodide (PI) following the manufacturer's instructions (Annexin V-FITC Apoptosis Detection Kit I, 556547, BD Pharmingen ${ }^{\mathrm{TM}}$, BD Bioscience) after $6 \mathrm{~h}$ of incubation. Namely, hNECs were washed twice with PBS and re-suspended in $1 \mathrm{X}$ Annexin $\mathrm{V}$ binding buffer at a concentration of $1 \times 10^{6}$ cells $/ \mathrm{ml}$. One hundred $\mu 1$ of cell suspension was transferred to a $5 \mathrm{ml}$ culture tube and $5 \mu \mathrm{l}$ of annexin V-FITC and 5 $\mu 1$ of PI were added. Cells were incubated with annexin VFITC and PI for 15 min at RT in the dark. Finally, $400 \mu 1$ of $1 X$ binding buffer was added to each tube. Five hundred $\mu$ of cell suspension was placed on the microscopic slide by cytospin technique and visualized under the laser scanning confocal microscope LSM 510 (Carl Zeiss) with a 40x magnification lens. The FITC-labeled annexin V appeared green and the propidium iodide-labeled nuclei appeared red. The images were analyzed using LSM image examiner software (Carl Zeiss). Four different fields were counted independently and stained cells were differentiated into annexin-FITC+PI- cells (early apoptotic cells) and annexin-FITC \pm PI+ (late apoptotic or already dead cells).

\section{Statistical analysis}

Statistical analysis was performed with GraphPad software Prism 4 (http://www.graphpad.com/prism /Prism.htm). All

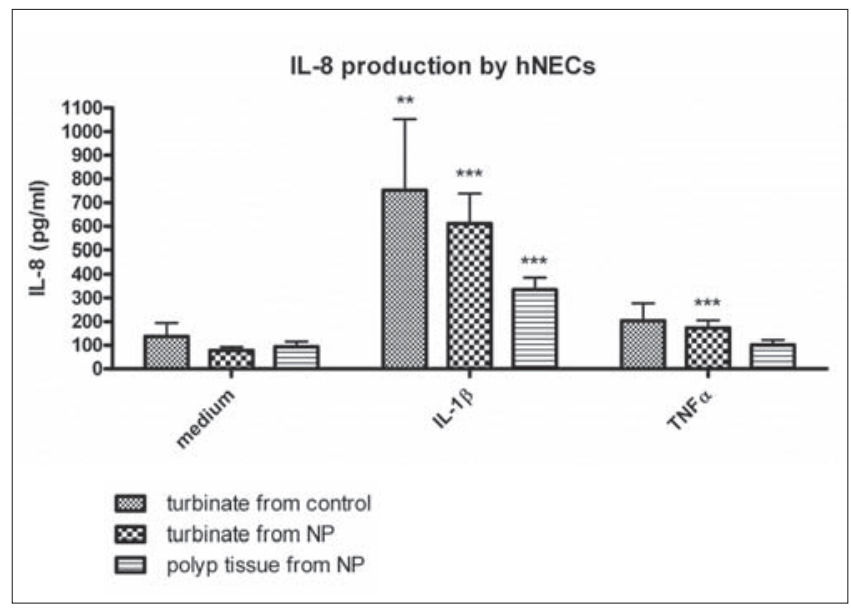

Figure 2. Effects of pro-inflammatory cytokines on IL-8 production. Production of IL-8 by hNECs upon incubation with pro-inflammatory cytokines IL- $1 \beta$ and TNF $\alpha$ is compared to the medium. Levels of IL- 8 are expressed in $\mathrm{pg} / \mathrm{ml}$ as measured by ELISA in the supernatants of hNECs cultures. ${ }^{*} \mathrm{p}<0.05, * * \mathrm{p}<0.01, * * * \mathrm{p}<0.001$ compared to medium condition of the same patient group. Control patients $n=13$, $\mathrm{NP}$ (nasal polyp patients) $\mathrm{n}=12$.

outcome variables were compared using non-parametrical tests. The Mann Whitney-U test was used for between-group comparison. For stimulation experiments and dose-dependent within-group comparison Wilcoxon signed-rank test was performed. A difference was considered to be significant when $\mathrm{p}$ $<0.05$. Data are expressed as mean with error bars expressing standard error of the mean.

\section{RESULTS}

IL-8 production by freshly isolated human nasal epithelial cells (hNECS) stimulated with/without IL-1 $\beta$ and TNF- $\alpha$

Nasal epithelial cells were freshly isolated from inferior turbinate of control and NP patients as well as from the polyp tissue taken from NP patients. Human NECs ( 1 x $10^{5}$ cells $\left./ \mathrm{ml}\right)$ were incubated in medium for $24 \mathrm{~h}$ in order to evaluate the basal IL- 8 levels in supernatants. IL- 8 was detectable in all experimental conditions without significant differences in IL-8 levels between the three groups (Figure 2). 1 × $10^{5}$ cells $/ \mathrm{ml}$ hNECs were stimulated with pro-inflammatory cytokines IL$1 \beta$ and TNF- $\alpha$ for $24 \mathrm{~h}$ to evaluate IL- 8 production. Stimulation with IL-1 $\beta$ induced significantly higher absolute amounts of IL-8 in human NECs in all three groups (control turbinate $136.9 \pm 57.77$ vs. $752.2 \pm 300.2, \mathrm{p}<0.01$; turbinate from NP $77.83 \pm 15.37$ vs. $610.8 \pm 127.6, \mathrm{p}<0.001$; polyp tissue $93.85 \pm 22.25$ vs. $335.1 \pm 50.38, \mathrm{p}<0.001$, Figure 2$)$. TNF- $\alpha$ had less effect on IL-8 production and significant up-regulation of IL- 8 by TNF- $\alpha$ was seen only in hNECs isolated from nasal turbinate of NP patients.

In addition, we also evaluated whether allergy or usage of nasal steroids would affect IL-8 production by hNECs. Patients who are allergic or who were using nasal steroids did not show any difference in IL-8 production under baseline conditions or 


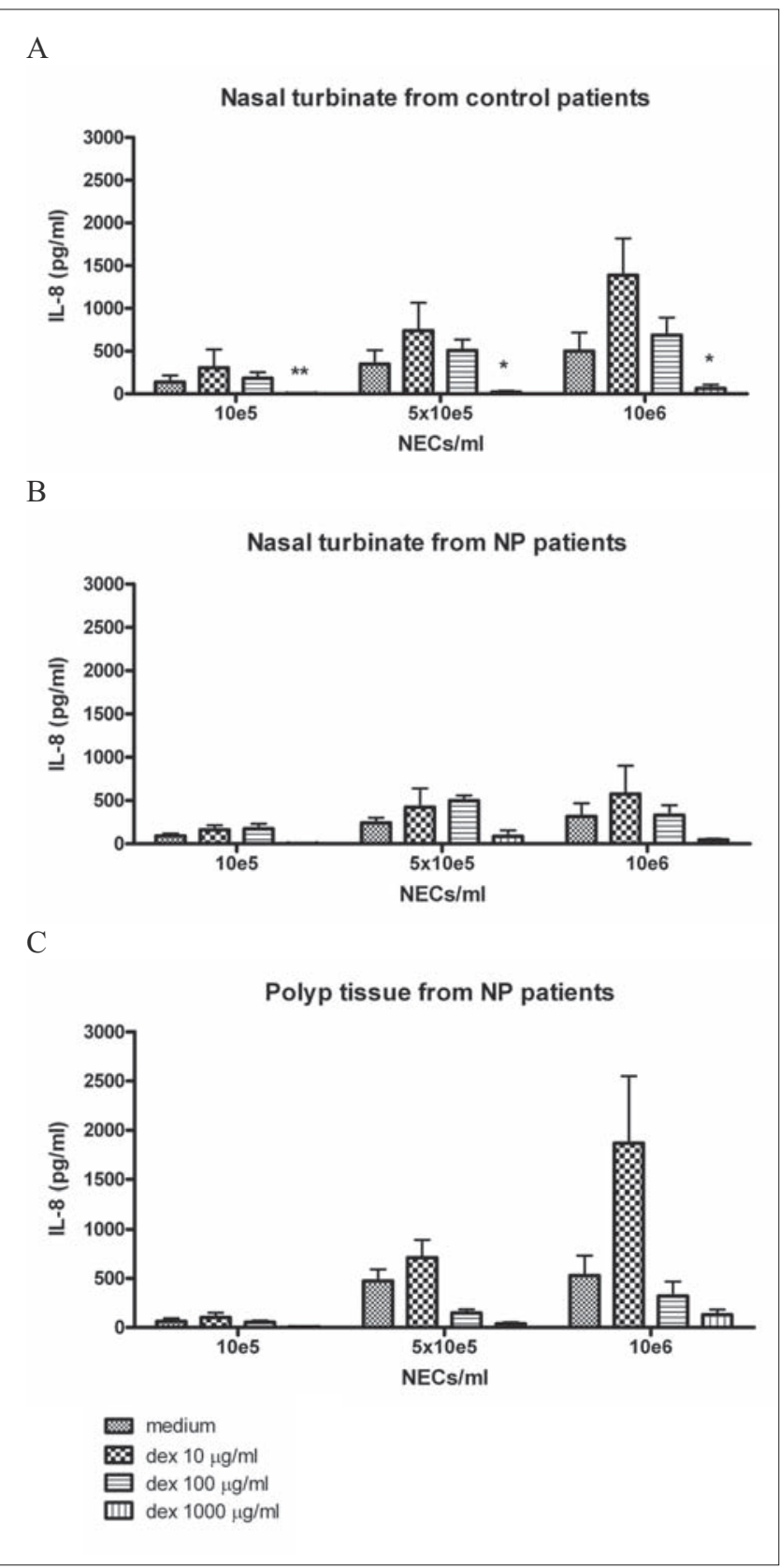

Figure 3. Effect of dexamethasone on IL-8 production. Production of IL-8 by hNECs upon stimulation with three different doses of dexamethasone $(10,100,1000 \mu \mathrm{g} / \mathrm{ml})$ is compared to the medium. The highest dose of dexamethasone significantly down-regulated IL-8 production in the hNECs isolated from nasal turbinate of control patients $(* \mathrm{p}<0.05, * * \mathrm{p}<0.01)$ compared to the medium. A) hNECs isolated from inferior turbinate of control patients $(\mathrm{n}=8), \mathrm{B}) \mathrm{hNECs}$ isolated from inferior turbinate of NP patients $(n=3), C)$ hNECs isolated from nasal polyp tissue taken from NP patients $(n=5)$.

when stimulated with pro-inflammatory cytokines compared to non-allergic and non-steroid using patients regardless of the tissue source (data not shown).

\section{IL-8 production by hNECS in response to dexamethasone}

Dexamethasone is a potent anti-inflammatory drug of the steroid family. To investigate the direct effect of dexamethasone on IL-8 production by NECs, we incubated different numbers of freshly isolated hNECs with three different doses of dexamethasone $(10,100,1000 \mu \mathrm{g} / \mathrm{ml})$. Dexamethasone at low dose $(10$ $\mu \mathrm{g} / \mathrm{ml}$ ) did not significantly alter IL-8 production by hNECs isolated from NP and control patients (in control patients for $1 \mathrm{x}$ $10^{5}$ cells/ml IL- 8 levels in the medium are $139.1 \pm 77.30$ vs. 307.1 \pm 214.7 in the condition with lowest dexamethasone concentration, $\mathrm{p}=0.426$; for $5 \times 10^{5}$ cells $/ \mathrm{ml} 349.1 \pm 162.2$ vs. $740.8 \pm$ $324.7, \mathrm{p}=0.156$; for $1 \times 10^{6}$ cells $/ \mathrm{ml} 502.2 \pm 216.9$ vs. $1390 \pm$ $429.5, \mathrm{p}=0.156$; Figure $3 \mathrm{~A}$ ). In contrast, the highest dose of dexamethasone $(1000 \mu \mathrm{g} / \mathrm{ml})$ completely abolished IL-8 production by hNECs (in control patients for $1 \times 10^{5}$ cells/ml IL-8 levels in the medium are $139.1 \pm 77.30$ vs. $3.633 \pm 1.305$ in the condition with highest dexamethasone concentration, $\mathrm{p}=0.004$; for $5 \times 10^{5}$ cells $/ \mathrm{ml} 349.1 \pm 162.2$ vs. $22.13 \pm 14.94, \mathrm{p}=0.016$; for $1 \mathrm{x}$ $10^{6}$ cells $/ \mathrm{ml} 502.2 \pm 216.9$ vs. $63.29 \pm 44.87, \mathrm{p}=0.031$; Figure 3 A). This finding was significant only for hNECs isolated from healthy nasal turbinate (Figure $3 \mathrm{~B}$ and $\mathrm{C}$ ).

When increasing numbers of hNECs were incubated with the same dose of dexamethasone, we observed the same trends in IL-8 production in response to dexamethasone in all hNECs. This was observed in hNECs isolated from either polyp tissue, inferior turbinate from both NP and control patients (Figure 3 A-C).

\section{Induction of apoptosis of hNECs by dexamethasone}

In the previous experiment it was shown that high doses of dexamethasone decreased IL-8 production by hNECs whereas low doses did not alter IL-8 levels. We speculated that this effect is due to the induction of apoptosis of hNECs by dexamethasone. To prove that dexamethasone has a pro-apoptotic effect on hNECs, freshly isolated hNECs were incubated with different doses of dexamethasone and stained with trypan-blue to estimate the cell viability and with annexin V-FITC and PI to evaluate the degree of apoptosis. Trypan-blue staining of $1 \mathrm{x}$ $10^{5}$ cells/ml freshly isolated hNECs from control turbinates showed loss of cell viability with increasing doses of dexamethasone (Figure $4 \mathrm{~A}$ ), indicating that hNECs undergo faster cell death in the presence of dexamethasone. This finding was additionally supported by the annexin V-FITC/PI staining (Figure 4B and C). hNECs incubated with medium alone or low doses of dexamethasone $(10 \mu \mathrm{g} / \mathrm{ml})$ had more annexin V-FITC+ PI- cells indicating an early apoptotic stage, whereas numbers of annexin V-FITC+PI+ cells (late apoptotic cells) increased with the higher concentrations of dexamethasone (Figure $4 \mathrm{~B}$ and $\mathrm{C}$ ).

\section{DISCUSSION}

We here present a novel technique for studying human nasal epithelial cells in vitro which enables investigating the effects of different pro-inflammatory stimuli on hNECs and dissecting their contribution to NP disease. This technique overcomes the problems with immortalized cell lines whose features and immunological responses may significantly differ from primary 


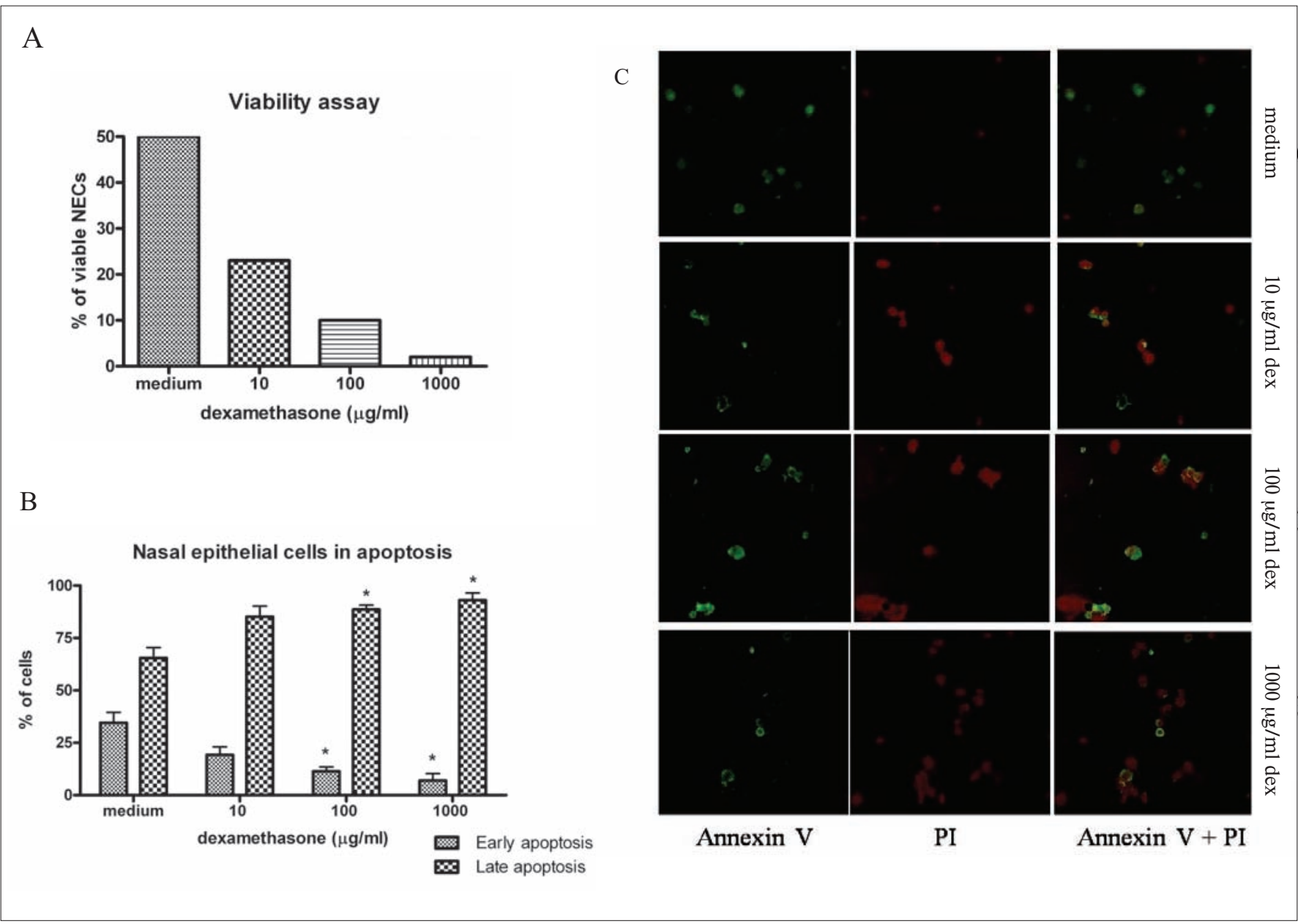

Figure 4. Apoptosis of hNECs. A) hNECs isolated from inferior turbinate of one healthy donor were incubated with increasing doses of dexamethasone for $24 \mathrm{~h}$ and stained with trypan-blue. Number of viable cells decreases with increasing dexamethasone concentrations (representative graph from one patient). B) Graph representation of the counted early and late apoptotic cells. Four different fields were counted and apoptotic cells were differentiated into early (green) and late (green and red) apoptotic cells. Number of apoptotic cells induced by dexamethasone was compared to the medium $(* \mathrm{p}<0.05)$. C) NECs incubated with increasing doses of dexamethasone for $6 \mathrm{~h}$ and stained with annexin V-FITC (green) and PI (red). Annexin V-FITC + PI- cells are green and indicate early apoptosis whereas annexin V-FITC + PI+ are green and red and indicate late apoptotic and already dead cells. Photographs were taken by confocal microscope.

cell cultures. Current protocols for isolating nasal epithelial cells imply long term incubation of epithelial cells which not only alters the phenotypical characteristics of hNECs, but may also change immune responses of hNECs ${ }^{(10-12)}$. Here, a short isolation protocol is described, i.e. a fast method for obtaining pure nasal epithelial cells with minimal effects on epithelial cells' phenotype and immunologic behavior.

One of the aims of this paper was to investigate the contribution of nasal epithelial cells to the production of IL-8, as IL-8 is known to be strongly up-regulated in CRSwithNP in parallel with typical Th2 cytokines like IL-5 ${ }^{(22,23)}$. Our data do not point towards a major contribution of nasal epithelial cells to IL-8 production in NP disease. Both inferior turbinate hNECs of control and NP patients as well as hNECs from polyp tissue of NP patients produced similar amounts of IL- 8 under baseline conditions. This observation is consistent with a study by Mullol et al. ${ }^{(33)}$, showing no difference in production of IL-8,
IL-6, GM-CSF and other cytokines between hNECs isolated from nasal mucosa of healthy donors and polyp tissue of NP patients. Therefore, IL- 8 production by nasal epithelial cells does not discriminate between nasal polyp tissue and healthy mucosa.

It has been reported that pro-inflammatory cytokines such as IL-1 $\beta$ and TNF- $\alpha$ induce or modulate IL- 8 expression in human airway epithelial cells ${ }^{(5,8,16)}$. Our data confirm that IL$1 \beta$ strongly induces IL-8 production in human nasal epithelial cells from all three groups, whereas TNF- $\alpha$ has very little effect on hNECs in terms of IL-8 production. Similarly to the basal levels, IL-8 production induced by the pro-inflammatory cytokine IL-1 $\beta$ was not significantly different between hNECs isolated from nasal turbinate or polyp tissue either from healthy or NP patients. These results suggest that there is no intrinsic difference in IL-8 production between the epithelial cells from healthy mucosa or nasal polyp tissue, neither in 
unstimulated conditions nor upon stimulation with pro-inflammatory cytokines. On the other hand, the local environment in NP tissue is highly inflammatory creating strong stimulus for hNECs to produce IL-8. This observation, together with the IL-8 production by eosinophils, which are highly present in NP tissue, may account for the higher levels of IL-8 in NP tissue compared to healthy nasal mucosa ${ }^{(23)}$. In our group, allergic status or usage of intranasal corticosteroids had almost no effect on the IL-8 production in hNECs.

Previously, it has been reported that hNECs from NP tissue produce more IL-8 than hNECs from healthy donors, which was reduced by dexamethasone treatment ${ }^{(7)}$. However, the same authors also showed no difference in IL-8 production between hNECs from healthy mucosa and NP tissue ${ }^{(33)}$. As mentioned earlier, no difference was observed here between hNECs from three sources in terms of basal IL- 8 production. Interestingly, high dose of dexamethasone abolished the production of IL-8 whereas lower doses had almost no effect on IL-8 levels. We hypothesized that the inhibitory effect of dexamethasone on IL-8 production at the lower doses is masked by the induction of apoptosis which might lead to the release and secretion of pre-synthesized IL-8 from an early apoptotic nasal epithelial cell. Higher doses of dexamethasone probably have a much stronger inhibitory effect, which cannot be influenced by the level of hNECs apoptosis. Indeed, it has already been shown that dexamethasone can induce apoptosis of airway epithelial cells in both humans ${ }^{(6,34)}$ and mice ${ }^{(35)}$. Our results thus confirm that dexamethasone induces apoptosis of hNECs. hNECs incubated with dexamethasone lose their viability in a concentration-dependent manner and enter apoptosis faster than cells grown in the medium without dexamethasone. The mechanisms by which dexamethasone induces apoptosis of hNECs and release of IL- 8 still remain to be explained. The effects of dexamethasone in terms of IL-8 secretion should probably be explored on the post-translational level or on the level of exocytosis of vesicles containing presynthesized IL-8. Proteins involved in degradation of IL-8 mRNA might also be affected by dexamethasone since it is known that dexamethasone strongly affects the stability of IL-8 mRNA $^{(30)}$.

In conclusion, we here present a novel technique for epithelial cell isolation and culture, showing that IL-8 production does not discriminate between human nasal epithelial cells isolated from nasal turbinate or nasal polyp tissue of control and NP patients. In addition, dexamethasone induces apoptosis of hNECs with concomitant reduction of IL- 8 secretion by hNECs.

\section{ACKNOWLEDGMENTS}

This work was supported by a grant of the Interuniversity Attraction Pole Program of the Belgian State, Belgian Science Policy, by a grant of the Fund for Scientific Research
Vlaanderen and by a grant from the Research Council of the Katholieke Universiteit Leuven (KULeuven). S. Bobic was the recipient of a $\mathrm{PhD}$ fellowship from the Research Council of the KULeuven. P. Hellings is the recipient of a senior researcher fellowship from the Fund for Scientific Research Vlaanderen.

\section{AUTHORSHIP CONTRIBUTION}

Major part of the research has been conducted in the host lab of C. van Drunen and W. Fokkens in the Amsterdam Medical Center. C. van Drunen, W. Fokkens and P. Hellings designed the research. P. Hellings and M. Jorissen harvested nasal tissue from healthy and NP patients. Isolation and stimulation of nasal epithelial cells was done by P. Hellings. I. Callebaut and V. Hox actively contributed in the experimental part of the study. First author performed experiments related to apoptosis assay, analyzed data and wrote the paper.

\section{CONFLICT OF INTEREST}

Authors declare no conflict of interest.

\section{REFERENCES}

1. King C, Brennan S, Thompson PJ, et al. Dust mite proteolytic allergens induce cytokine release from cultured airway epithelium. J Immunol 199; 161: 3645-3651.

2. Daffern PJ, Jagels MA, Hugli TE. Multiple epithelial cell-derived factors enhance neutrophil survival. Regulation by glucocorticoids and tumor necrosis factor-alpha. Am J Respir Cell Mol Biol 1999; 21: 259-267.

3. Daffern PJ, Jagels MA, Saad JJ, et al. Upper airway epithelial cells support eosinophil survival in vitro through production of GMCSF and prostaglandin E2: regulation by glucocorticoids and TNF-alpha. Allergy Asthma Proc 1999; 20:243-253.

4. Black HR, Yankaskas JR, Johnson LG, et al. Interleukin-8 production by cystic fibrosis nasal epithelial cells after tumor necrosis factor-alpha and respiratory syncytial virus stimulation. Am J Respir Cell Mol Biol 1998; 19: 210-215.

5. Coulter KR, Wewers MD, Lowe MP, et al. Extracellular regulation of interleukin (IL)-1beta through lung epithelial cells and defective IL-1 type II receptor expression. Am J Respir Cell Mol Biol 1999; 20: 964-975.

6. Dorscheid DR, Wojcik KR, Sun S, et al. Apoptosis of airway epithelial cells induced by corticosteroids. Am J Respir Crit Care Med 2001; 164 (10 Pt 1): 1939-1947.

7. Mullol J, Xaubet A, Gaya A, et al. Cytokine gene expression and release from epithelial cells. A comparison study between healthy nasal mucosa and nasal polyps. Clin Exp Allergy 1995; 25: 607-615.

8. Rudack C, Maune S, Eble J, et al. The primary role in biologic activity of the neutrophil chemokines IL-8 and GRO-alpha in cultured nasal epithelial cells. J Interferon Cytokine Res 2003; 23: 113-123.

9. Vroling AB, Jonker MJ, Luiten $\mathrm{S}$, et al. Primary nasal epithelium exposed to house dust mite extract shows activated expression in allergic individuals. Am J Respir Cell Mol Biol 2008; 38: 293-299.

10. Agu RU, Jorissen M, Willems $T$, et al. In-vitro nasal drug delivery studies: comparison of derivatised, fibrillar and polymerised collagen matrix-based human nasal primary culture systems for nasal drug delivery studies. J Pharm Pharmacol 2001; 53: 1447-1456.

11. Gruenert DC, Finkbeiner WE, Widdicombe JH. Culture and transformation of human airway epithelial cells. Am J Physiol 1995; 268 (3 Pt 1): L347-L360.

12. Yamaya M, Finkbeiner WE, Chun SY, et al. Differentiated structure and function of cultures from human tracheal epithelium. Am J Physiol 1992; 262 (6 Pt 1): L713-L724. 
13. Huvenne W, Callebaut I, Reekmans K, et al. Staphylococcus aureus enterotoxin $\mathrm{B}$ augments granulocyte migration and survival via airway epithelial cell activation. Allergy 2010.

14. KleinJan A, Dijkstra MD, Boks SS, et al. Increase in IL-8, IL-10, IL-13, and RANTES mRNA levels (in situ hybridization) in the nasal mucosa after nasal allergen provocation. J Allergy Clin Immunol 1999; 103 (3 Pt 1): 441-450.

15. O'Brien GJ, Riddell G, Elborn JS, et al. Staphylococcus aureus enterotoxins induce IL-8 secretion by human nasal epithelial cells. Respir Res 2006; 7: 115.

16. Cromwell O, Hamid Q, Corrigan CJ, et al. Expression and generation of interleukin-8, IL-6 and granulocyte-macrophage colonystimulating factor by bronchial epithelial cells and enhancement by IL-1 beta and tumour necrosis factor-alpha. Immunology 1992; 77: 330-337.

17. Kawaguchi M, Kokubu F, Kuga H, et al. Modulation of bronchial epithelial cells by IL-17. J Allergy Clin Immunol 2001; 108: 804809.

18. Jones CE, Chan K. Interleukin-17 stimulates the expression of interleukin-8, growth-related oncogene-alpha, and granulocytecolony-stimulating factor by human airway epithelial cells. Am J Respir Cell Mol Biol 2002; 26: 748-753.

19. Mullol J, Baraniuk JN, Logun C, et al. Endothelin-1 induces GMCSF, IL-6 and IL- 8 but not G-CSF release from a human bronchial epithelial cell line (BEAS-2B). Neuropeptides 1996; 30: 551-556.

20. Mullol J, Baraniuk JN, Pitale M, et al. Vasoactive intestinal peptide (VIP) induces IL-6 and IL-8, but not G-CSF and GM-CSF release from a human bronchial epithelial cell line. Neuropeptides 1997; 31: 119-124.

21. Baggiolini M, Walz A, Kunkel SL. Neutrophil-activating peptide1/interleukin 8, a novel cytokine that activates neutrophils. J Clin Invest 1989; 84: 1045-1049.

22. Van Zele T, Claeys S, Gevaert P, et al. Differentiation of chronic sinus diseases by measurement of inflammatory mediators. Allergy 2006; 61: 1280-1289.

23. Allen JS, Eisma R, Leonard G, et al. Interleukin-8 expression in human nasal polyps. Otolaryngol Head Neck Surg 1997; 117: 535 541.

24. Ebbens FA, Rinia $A B$, Luiten $S$, et al. Increased neutrophil chemoattractant IL-8 is characteristic of all nasal polyp tissue specimens. Ebbens FA, editor. Controversies in chronic rhinosinusitis, PhD Thesis. 2009; 29-40.

25. Yun YS, Choi JC, Jang TY, et al. Expression of Transforming Growth Factor-beta(TGF-beta) Family in Nasal Polyps and Postoperative Polypoid Mucosa after Functional Endoscopic Sinus Surgery. J Rhinol 1997; 4: 111-115.

26. Watelet JB, Demetter P, Claeys C, et al. Neutrophil-derived metalloproteinase- 9 predicts healing quality after sinus surgery. Laryngoscope 2005; 115: 56-61.
27. Fokkens W, Lund V, Mullol J. EP3OS 2007: European position paper on rhinosinusitis and nasal polyps 2007. A summary for otorhinolaryngologists. Rhinology 2007; 45: 97-101.

28. Eddleston J, Herschbach J, Wagelie-Steffen AL, et al. The antiinflammatory effect of glucocorticoids is mediated by glucocorticoid-induced leucine zipper in epithelial cells. J Allergy Clin Immunol 2007; 119: 115-122

29. Scheinman RI, Cogswell PC, Lofquist AK, Baldwin AS, Jr. Role of transcriptional activation of I kappa B alpha in mediation of immunosuppression by glucocorticoids. Science 1995; 270 (5234): 283-286.

30. Chang MM, Juarez M, Hyde DM, et al. Mechanism of dexamethasone-mediated interleukin-8 gene suppression in cultured airway epithelial cells. Am J Physiol Lung Cell Mol Physiol 2001; 280: L107-L115.

31. Nishi Y, Takeno S, Ishino T, et al. Glucocorticoids suppress NFkappaB activation induced by LPS and PGN in paranasal sinus epithelial cells. Rhinology 2009; 47: 413-418

32. Fukakusa M, Bergeron C, Tulic MK, et al. Oral corticosteroids decrease eosinophil and $\mathrm{CC}$ chemokine expression but increase neutrophil, IL-8, and IFN-gamma-inducible protein 10 expression in asthmatic airway mucosa. J Allergy Clin Immunol 2005; 115: 280-286.

33. Mullol J, Lopez E, Roca-Ferrer J, et al. Effects of topical antiinflammatory drugs on eosinophil survival primed by epithelial cells. Additive effect of glucocorticoids and nedocromil sodium. Clin Exp Allergy 1997; 27: 1432-1441.

34. Tse R, Marroquin BA, Dorscheid DR, et al. Beta-adrenergic agonists inhibit corticosteroid-induced apoptosis of airway epithelial cells. Am J Physiol Lung Cell Mol Physiol 2003; 285: L393-L404.

35. Dorscheid DR, Low E, Conforti A, et al. Corticosteroid-induced apoptosis in mouse airway epithelium: effect in normal airways and after allergen-induced airway inflammation. J Allergy Clin Immunol 2003; 111:360-366

\section{Peter Hellings \\ Department of Otorhinolaryngology \\ University Hospital Leuven \\ Kapucijnevoer 33 \\ 3000 Leuven \\ Belgium}

Tel: +32-16-332 342

Fax: +32-16-343 835

E-mail: Peter.Hellings@uzleuven.be 